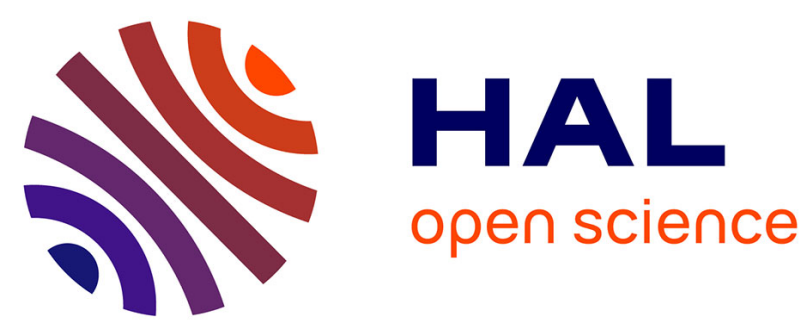

\title{
Return to Sport Among French Alpine Skiers After an Anterior Cruciate Ligament Rupture
}

\author{
Amal Haïda, Nicolas Coulmy, Frédéric Dor, Juliana Antero, Andy Marc,
} Thibaut Ledanois, Claire Tourny, Marie Philippe Rousseaux-Blanchi, Pierre Chambat, Adrien Sedeaud, et al.

\section{To cite this version:}

Amal Haïda, Nicolas Coulmy, Frédéric Dor, Juliana Antero, Andy Marc, et al.. Return to Sport Among French Alpine Skiers After an Anterior Cruciate Ligament Rupture: Results From 1980 to 2013. The American Journal of Sports Medicine, 2016, 44 (2), pp.324 - 330. 10.1177/0363546515612764 . hal01774985

\section{HAL Id: hal-01774985 https://hal-insep.archives-ouvertes.fr/hal-01774985}

Submitted on 27 Apr 2018

HAL is a multi-disciplinary open access archive for the deposit and dissemination of scientific research documents, whether they are published or not. The documents may come from teaching and research institutions in France or abroad, or from public or private research centers.
L'archive ouverte pluridisciplinaire HAL, est destinée au dépôt et à la diffusion de documents scientifiques de niveau recherche, publiés ou non, émanant des établissements d'enseignement et de recherche français ou étrangers, des laboratoires publics ou privés. 


\title{
Return to Sport Among French Alpine Skiers After an Anterior Cruciate Ligament Rupture
}

\section{Results From 1980 to 2013}

\author{
Amal Haida, ${ }^{\star y z} \mathrm{PhD}$, Nicolas Coulmy, ${ }^{\S} \mathrm{PhD}$, Frédéric Dor, ${ }^{\mathrm{y}} \mathrm{PhD}$, \\ Juliana Antero-Jacquemin, ${ }^{y \|}$ MSc, Andy Marc, ${ }^{y}$ MSc, Thibaut Ledanois, ${ }^{y}$ MSc, \\ Claire Tourny, ${ }^{\mathrm{Z}} \mathrm{PhD}$, Marie Philippe Rousseaux-Blanchi, ${ }^{\S} \mathrm{PhD}$, Pierre Chambat, ${ }^{\S} \mathrm{PhD}$, \\ Adrien Sedeaud, ${ }^{\mathrm{y}} \mathrm{PhD}$, and Jean-Franæois Toussaint, ${ }^{\mathrm{y} \|\{\mathrm{PhD}}$ \\ Investigation performed at the Institute of bioMedical Research and Epidemiology in Sports, \\ Paris, France
}

\begin{abstract}
Background: There is little known about return to sport and performance after anterior cruciate ligament $(A C L)$ tear in high-level alpine skiers.
\end{abstract}

Purpose: To analyze the parameters that influence the return to sport and performance after an ACL tear in French alpine skiers from 1980 to 2013.

Study Design: Descriptive epidemiology study.

Methods: The study population included 239 male and 238 female skiers who competed on the national French alpine ski team for at least 1 season between 1980 and 2013 in the speed (downhill and super-G) and technical disciplines (giant slalom and slalom). Two groups were formed: group 1 (G1) included athletes who had sustained an ACL rupture, and group 2 (G2) included athletes who had never sustained an ACL rupture. Three performance indicators were selected: International Ski Federation (FIS) points calculation, FIS ranking, and podium finishes in the World Cup, World Championships, and Olympic Games.

Results: The first-decile FIS points and international FIS ranking showed that G1 skiers obtained better performance than did G2 skiers. The mean 6 SD career length of G1 skiers (men, 7.964 .7 years; women, 7.1 64.1 years) was longer than that of G2 skiers (men, $4.5 \pm 3.3$ years; women, $4.2 \pm 3.5$ years). In addition, $12.8 \%$ (61 of 477 ) of the skiers achieved at least a podium finish during their careers: $23.0 \%$ (34 of 148) in G1 and 8.3\% (27 of 329) in G2. The mean age at ACL rupture was $22 . \pm 64.1$ years for men and $19.9 \pm 3.5$ years for women. In G1, 55 podiums were achieved before ACL rupture and 176 after in all competitions. Skiers who improved their performances after ACL rupture were significantly younger (men, $22.2 \pm 3.0$ years; women, $18.7 \pm 2.2$ years; $P<.0001$ ) at the time of injury than those showing a performance deterioration after ACL rupture (men, $25.3 \pm$ 4.2 years; women, $22.4 \pm 4.0$ years). All skiers who had ACL tears continued their competitive careers after the injury.

Conclusion: The overall results showed that it is possible to return to preinjury or even higher levels of performance after an ACL rupture and that age is the main element that guides postsurgical recovery.

Keywords: alpine skiing; $A C L$; return to performance

\begin{abstract}
Alpine skiing is the most popular winter sport in the world, and its participants are exposed to a high injury risk. ${ }^{21}$ Recent studies from the Data Surveillance System of the International Ski Federation (FIS) showed that the risk of injury in alpine skiing is high. ${ }^{8,9}$ The lower limbs are the most commonly affected, with $58.1 \%$ of total injuries. The part of the body mostly affected is the knee, representing $35.6 \%$ of injuries, of which $54.4 \%$ are severe injuries causing an absence $>28$ days in training and competition. ${ }^{8}$ Knee
\end{abstract}

trauma is common among professional and recreational skiers, and the most common diagnosis is the rupture of the anterior cruciate ligament (ACL), accounting for 35.6\% of total injuries and $67.9 \%$ of knee injuries. ${ }^{8,12}$ According to Flørenes et al, $^{8}$ speed disciplines are more traumatic than technical disciplines, with a respective incidence of 17.2 and 4.9 injuries over 1000 runs and 7.0 and 0.9 knee injuries per 1000 runs.

To our knowledge, return to sport and postinjury performance after ACL rupture in elite athletes have not been studied in alpine skiing. Researchers have investigated return to sport after an ACL rupture in the overall active population..$^{2,7,10,24}$ Intentions of returning to sport, levels of participation (return to the competition or not), and 
factors that affect return to sport after ACL reconstruction have been analyzed in the scientific literature. ${ }^{2,24}$ Finally, several studies have suggested that return to sport and the probability of returning to preinjury levels depend more on the patient's personality than the functional knee reconstruction. ${ }^{1,7,10}$

In this context, the purpose of this retrospective epidemiologic study was to analyze the influence of the ACL rupture on French alpine skiers' postinjury performances from 1980 to 2013.

\section{METHODS}

\section{Study Design}

This study used a research protocol qualified as noninterventional, in which "all acts are performed in a normal manner, without any supplemental or unusual procedure of diagnosis or monitoring" (article L1121-1 of the French public health code). According to law, its approval therefore did not fall under the responsibility of a committee for the protection of persons. For these reasons, it was not necessary to obtain informed consent from the athletes evaluated. This study was designed and monitored by the scientific committee of the Institute of bioMedical Research and Epidemiology in Sports.

\section{Study Population and Period}

The study population included all athletes, 239 men and 238 women, who competed on the national French alpine skiing team for at least 1 full season between 1980 and 2013 in all events: downhill and super-G (speed disciplines) and giant slalom and slalom (technical disciplines). Skiers were divided into 2 groups: group 1 (G1), those who had sustained an ACL tear; and group 2 (G2), those who had never sustained an ACL tear. All skiers had a specialty (speed, technique, or polyvalent), but they competed in all disciplines. No other injuries were considered in this study.

\section{Competitions}

Only international-level competitions were taken into account. The World Cup takes place every year and determines the best skier of the year in each discipline. About 14 events are run in each discipline throughout the season. The World Championships are held every 2 years and the Olympic Games every 4 years, and winners are rewarded for 1 race in each discipline.

\section{Data Collection}

\section{Skier Characteristics}

Databases of the French Ski Federation were used to collect the following information: name, sex, year of birth, year the skier joined and left the team, occurrence of ACL tear, and occurrence date.

\section{Performance Indicators}

Several performance indicators were selected, as follows.

FIS Points. The FIS points system applies to skiers older than 15 years who are participating in international competitions. Calculation of FIS points is established after each race, and it represents the sum of FIS points obtained during the race that day and a coefficient ("race penalty") obtained from previous racing. The closer a skier's FIS points is to zero, the better his or her performance. The best annual FIS points of each skier, for each discipline and for each season during his or her time in the national team, was collected on the FIS website. ${ }^{15}$ This website identifies FIS points starting from 1995. Age at ACL rupture of skiers who had improved or deteriorated performance after rupture was calculated for the best FIS points obtained before and after the injury.

FIS International Ranking. For each skier in each discipline and in each season in the team, the best international FIS ranking was collected from 1995 on the FIS website. ${ }^{15}$

Podium Finishes. All podium finishes in the World Cup, World Championship, and Olympic Games achieved by the alpine skiers of the national team were collected from the FIS website. ${ }^{15}$ Podiums finishes from 1980 to 2013 are available on the FIS website.

\section{Statistical Analysis}

Performance distribution (FIS points and international FIS ranking) was determined by decile (top decile of performances per athlete). The first decile is described in function of G1 and G2, sex, and discipline. The number of podium finishes was recorded as a percentage in the group.

The Student $t$ test was used to compare the mean career lengths of G1 and G2 in each discipline and for each sex. The same test was performed to compare the mean age at the moment of ACL rupture of skiers who improved and skiers whose performances deteriorated after ACL tear. The level of significance was set at $P<.05$.

Concerning the French top-10 performance data, performance modeling of FIS was constructed as a function of age. The best performance by age is fitted by a seconddegree polynomial function. ACL rupture incidence

\footnotetext{
*Address correspondence to Amal Haida, PhD, Institute of bioMedical Research and Epidemiology in Sports, 11 Avenue du Tremblay, Paris, 75012, France (email: amal.haida@gmail.com).

Institute of bioMedical Research and Epidemiology in Sports, Paris, France.

${ }^{z}$ Centre d'Etude des Transformations des Activités Physiques et Sportives-EA 3832, Rouen University, Mont Saint Aignan, France.

§French Ski Federation, Annecy, France.

"Paris Descartes University, Sorbonne Paris Cité, Paris, France.

${ }^{\{}$Center for Investigations in Sport Medicine, Hôtel-Dieu, Assistance Publique des Hô pitaux de Paris, Paris, France.

One or more of the authors has declared the following potential conflict of interest or source of funding: Financial assistance was provided by the Institut National du Sport, de l'Expertise et de la Performance and the Ministère des Droits des Femmes de la ville, de la jeunesse et des Sports.
} 


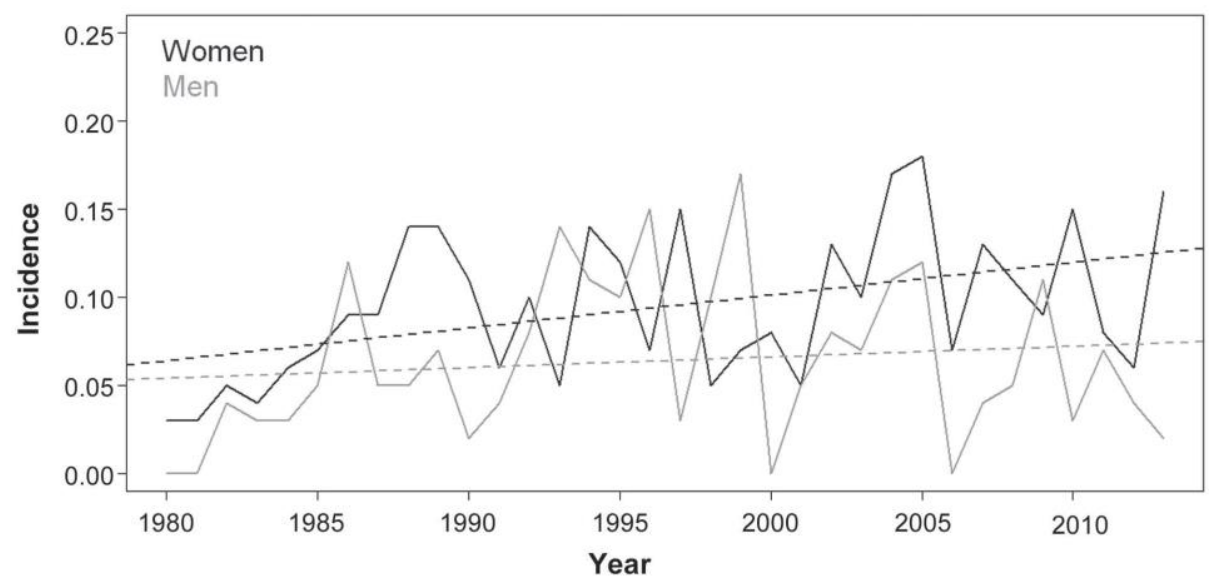

Figure 1. Incidence from 1980 to 2013: number of anterior cruciate ligament ruptures per number of skiers per year. Dashed lines indicate means.

(number of ACL ruptures per number of skiers per year) was calculated for each year from 1980 to 2013.

\section{RESULTS}

\section{Population}

From the 1980-1981 season to the $2012-2013$ season, 477 alpine skiers joined the French alpine ski team for at least 1 year. Among them, 148 skiers (67 men and 81 women) suffered ACL ruptures (71 in speed disciplines, 76 in technical disciplines, and 1 polyvalent), and 329 (172 men and 157 women) did not have any ACL rupture in their careers (164 in speed disciplines, 157 in technical disciplines, and 8 polyvalent).

\section{ACL Rupture Incidence}

The incidence ACL ruptures was 0.08 ( 0.07 for men, $r^{2}=0.22$; 0.09 for women, $r^{2}=0.27$ ) from 1980 to 2013 (Figure 1).

\section{Career Length}

From 1980 to 2013, the mean career length for G1 athletes was significantly longer than that of G2 athletes (Table 1). This difference was noted in the 2 sexes and in technical and speed disciplines. In G1 and G2, women began and ended their careers in the team significantly earlier than men $(P<.01)$. All skiers who had ACL tears continued their competitive careers after the injury.

The number of events per athlete was 9.9 for men in the ACL-tear group and 8.7 for those in the group without ACL tears. For women, it was 9.4 in the ACL-tear group and 8.6 in the group without tears. Statistically, the difference is not significant.

\section{Age at ACL Rupture}

The mean age at the first ACL tear was $21.1 \pm 4.0$ years. Women appeared to suffer the injury significantly earlier, with a mean age of $19.9 \pm 3.5$ years, compared with 22.6 \pm 4.1 years for men $(P<.0001)$.

\section{G1 and G2 Performances}

\section{Podium Finishes}

Among the 477 alpine skiers, $61(12.8 \%)$ had at least 1 podium finish at the Olympic Games, World Championships, and/or World Cup during their careers. From 148 athletes in G1, $34(23.0 \%)$ achieved at least 1 podium in their careers, and from 329 athletes in G2, 27 (8.3\%) got at least 1 podium.

\section{FIS Points and International FIS Rankings}

The analysis of the first decile of performance showed that the international FIS ranking of skiers in the national team (both sexes and disciplines included) was no higher than 26th and the maximum number of FIS points was 8.11. The international FIS ranking and FIS points were better for men than for women regardless of disciplines. In speed as in technical discipline, G1 athletes ranked better and had better FIS points than did G2 athletes (Table 2 ). The first decile of technical disciplines in G1 showed that men ranked better and had better FIS points than those of women (9.7th rank and 4.09 FIS points vs 15.5th place and 5.75 FIS points, respectively). The same trend was noted in G2 (men, 33rd rank and 7.58 FIS points; women, 51.8st rank and 12.61 FIS points).

In a comparison of pre- versus postinjury findings, athletes were able to improve their international FIS rankings and FIS points after the trauma (Table 3).

\section{Performance After ACL Rupture}

\section{Podium Finishes}

In G1, 34 athletes had at least 1 podium in their careers. On the whole, 55 podiums were achieved before ACL rupture and 176 after. In all competitions, men had 37 podiums before ACL rupture, compared with 86 after it; as for women, 18 podiums were achieved before the injury, against 90 after it. In the World Cup, 52 podiums were noted before ACL tear and 157 after. In the World 
TABLE 1

Career Length in the Study Groups by Discipline and Sex ${ }^{a}$

\begin{tabular}{|c|c|c|c|c|c|}
\hline \multirow[b]{2}{*}{ Discipline } & \multicolumn{2}{|c|}{$\mathrm{G} 1(\mathrm{n}=148)$} & \multicolumn{2}{|c|}{$\mathrm{G} 2(\mathrm{n}=329)$} & \multirow[b]{2}{*}{$P$ Value } \\
\hline & Career Length & Retirement Age & Career Length & Retirement Age & \\
\hline \multicolumn{6}{|l|}{ Men } \\
\hline Technical & $7.0 \pm 4.5$ & $26.6 \pm 4.8$ & $4.5 \pm 3.3$ & $22.7 \pm 4.1$ & $<.01$ \\
\hline Speed & $8.8 \pm 4.8$ & $26.8 \pm 4.7$ & $4.2 \pm 3.2$ & $23.3 \pm 4.5$ & $<.001$ \\
\hline Total & $7.9 \pm 4.7$ & $26.8 \pm 4.8$ & $4.5 \pm 3.3$ & $23.4 \pm 4.5$ & $<.001$ \\
\hline \multicolumn{6}{|l|}{ Women } \\
\hline Technical & $7.3 \pm 4.1$ & $24.0 \pm 4.2$ & $4.4 \pm 3.7$ & $20.8 \pm 3.5$ & $<.001$ \\
\hline Speed & $6.9 \pm 4.2$ & $23.9 \pm 4.2$ & $4.2 \pm 3.3$ & $20.7 \pm 3.6$ & $<.001$ \\
\hline Total & $7.1 \pm 4.1$ & $24.0 \pm 4.2$ & $4.2 \pm 3.5$ & $20.8 \pm 3.6$ & $<.001$ \\
\hline
\end{tabular}

${ }^{a}$ Values are presented as years, mean 6 SD. G1, skiers with an anterior cruciate ligament rupture; G2, skiers with no anterior cruciate ligament rupture.

TABLE 2

Description of FIS Points and International FIS Ranking by Sex, Discipline, and Group ${ }^{a}$

\begin{tabular}{|c|c|c|c|c|}
\hline \multirow{2}{*}{$\begin{array}{l}\text { First Decile of } \\
\text { Performance }\end{array}$} & \multicolumn{2}{|c|}{$\begin{array}{l}\text { International } \\
\text { FIS Ranking }\end{array}$} & \multicolumn{2}{|c|}{ FIS Points } \\
\hline & Men & Women & Men & Women \\
\hline \multicolumn{5}{|c|}{ Speed disciplines } \\
\hline G1 & 15.6 & 21.4 & 5.03 & 9.22 \\
\hline G2 & 37.9 & 42.1 & 10.9 & 14.62 \\
\hline \multicolumn{5}{|c|}{ Technical disciplines } \\
\hline G1 & 9.7 & 15.5 & 4.09 & 5.75 \\
\hline G2 & 33 & 51.8 & 7.58 & 12.61 \\
\hline
\end{tabular}

${ }^{a}$ FIS, International Ski Federation; G1, skiers with an anterior cruciate ligament rupture; G2, skiers with no anterior cruciate ligament rupture.

Championships, 1 podium finish was achieved before and 11 after. In the Olympic Games, 2 podium finishes were reached before ACL rupture, against 8 after it (Figure 2). If we divide the number of podium finishes by the number of races, there were 0.04 podiums per race before the trauma and 0.09 podiums per race after it.

\section{FIS Points and International FIS Ranking}

The skiers who improved their performances after the ACL rupture were significantly $(P<.0001)$ younger at the time of ACL tear (men, $22.2 \pm 3.0$ years; women, $18.7 \pm 2.2$ years) than were those with lower postinjury performance (men, $25.3 \pm 4.2$ years; women, $22.4 \pm 4.0$ years).

Similarly, in the international FIS ranking, men who improved their rankings after ACL rupture were younger at the time of injury $(22.0 \pm 3.0$ years $)$ than were those with lower post-ACL rupture rankings $(25.7 \pm 4.0$ years $)$ $(P<.0001)$. The same trend was noted among women, with a mean age of $18.8 \pm 2.3$ years at ACL rupture for those who improved their rankings after the injury and $22.1 \pm 4.0$ years for those whose postinjury rankings dropped $(P<.0001)$. For skiers who improved after an ACL
TABLE 3

Comparison of FIS Points and International FIS Ranking for G1 Before and After ACL Injury ${ }^{a}$

\begin{tabular}{lccccc}
\hline & \multicolumn{2}{c}{$\begin{array}{c}\text { International } \\
\text { FIS Ranking }\end{array}$} & & \multicolumn{2}{c}{ FIS Points } \\
\cline { 2 - 3 } \cline { 5 - 6 } $\begin{array}{l}\text { H'rrst Decile of } \\
\text { Performance }\end{array}$ & Men & Women & & Men & Women \\
\hline $\begin{array}{l}\text { Speed disciplines } \\
\quad \text { Before ACL injury }\end{array}$ & 19.3 & 87.4 & & 5.5 & 13.3 \\
$\quad$ After ACL injury & 15.2 & 5.6 & & 4.9 & 5.3 \\
Technical disciplines & & & & & \\
$\quad$ Before ACL injury & 33 & 36 & & 9 & 5.6 \\
After ACL injury & 7 & 14.7 & & 4 & 5.8 \\
\hline
\end{tabular}

${ }^{a} \mathrm{ACL}$, anterior cruciate ligament; FIS, International Ski Federation; G1, skiers with an ACL rupture.

rupture, the best performance was achieved on average after $3.8 \pm 3.1$ years for men and $3.1 \pm 2.5$ years for women after the ACL tear.

\section{DISCUSSION}

Return to sport and postinjury performance are not known among the alpine skiing elite after ACL rupture. The main results show that it is possible to find better performances after an ACL tear. This level depends on the age when the ACL rupture occurs.

\section{ACL Rupture and Performance Level}

In this study, G1 had better FIS points and international FIS rankings than did G2. At their best, G1 skiers had more podiums and better FIS points than did G2 skiers. Our results confirm those reported by Pujol et al, ${ }^{23}$ in which the incidence of ACL rupture was related to the performance level. The French skiers in the international top 30 were the ones who had more ACL ruptures than their counterparts. One hypothesis to explain a higher level among athletes who suffered ACL rupture is the recovery 


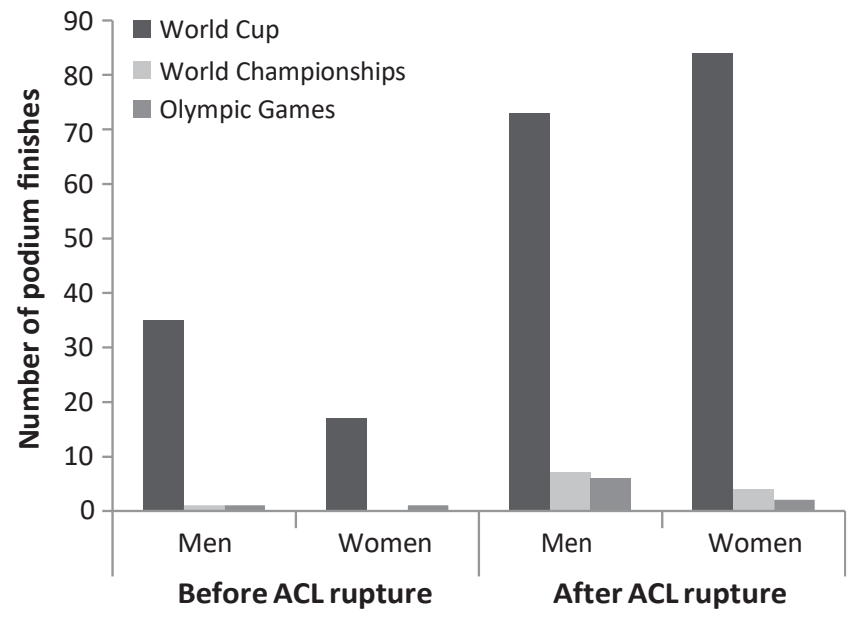

Figure 2. Number of podium finishes before and after anterior cruciate ligament rupture by sex and competition.

time after the injury. During ACL reconstruction, skiers stop all intensive trainings and competitions but remain under active recovery. This recovery may improve the physical and physiologic parameters of the athletes, optimizing their return to performance levels while providing rest from intense training. ${ }^{10,13}$ The psychological quality of the athletes is crucial to meet the requirements of the environment. One study reported that high-risk athletes (including alpine skiers) have a lower prevalence of anxiety or depression disorders than do athletes in low-risk sports. ${ }^{22}$ Athletes who seek extreme sensations are more liable to accidents. ${ }^{17}$ Risk taking, especially in downhill skiing, is a major risk factor of injury. ${ }^{5}$ Using the Zuckerman scale,${ }^{29}$ Webster et $\mathrm{al}^{28}$ reported that high-level skiers have a higher "thrill and adventure seeking" score (defined by a desire to engage in activities and sports of risk and adventure with unusual sensations) as compared with the general population. This score is also higher among skiers who have had an injury versus those who have never been injured. ${ }^{5}$ Athletes with significant injury rates have reported preferences for stimulants and thrill-seeking environments. ${ }^{20}$

\section{Return to Performance and Age}

The results show that skiers who suffered ACL tears were able to achieve podium success after injury, but it depended on their ages at the time of the ACL ruptures. Similarly, skiers who were able to improve their performances (FIS points and international FIS rankings) after an ACL injury were significantly younger than those who did not improve their performances after the injury. Women suffered ACL tears at $19.9 \pm 3.5$ years of age on average, 3.1 years after their entry in the high-career team, and men were injured at $22.6 \pm 4.1$ years of age on average, 4.7 years after their entry in the high-career team. Age is a crucial point in terms of return to performance, owing to the relationship between it and performance. ${ }^{3,19}$ Age is characterized by an initial phase of exponential growth, reflecting the development of physical abilities; a second phase corresponding to the optimal performance, including peak performance; and a third phase of regression, in which performance decreases. Berthelot et $\mathrm{al}^{4}$ showed the age of peak performance of the best world athletes to be 26.0 years in track-and-field events and 21.0 years in swimming. The age at peak performance of top-10 tennis players is 21.5 years for women and 24.1 years for men. ${ }^{11}$ In our population, the age of peak performance in top-10 skiers was 25.1 years for men and 25.3 years for women. The skiers who improved their performances after ACL rupture were young and had not yet reached the age of peak performance. This explains their higher probability of achieving better performance after injury. Men who had better FIS points after injury had a known ACL tear at $22.2 \pm 3.0$ years on average. In women, skiers who had improved performance (FIS points) suffered an ACL rupture at $18.7 \pm 2.2$ years on average. Conversely, skiers who did not find a better postinjury level of performance had an ACL tear later, thereby reducing the probabilities of reaching optimal performance after ACL rupture.

\section{ACL Rupture by Sex and Discipline}

After basketball, skiing is the highest-risk sport for women in terms of number of ACL rupture occurrences. ${ }^{27}$ The female:male ratio of ACL tear incidences is 1.3:1; therefore, women's risk of ACL rupture is 30\% higher than men's. Many studies report a difference in rates of knee injuries between men and women. Among recreational as well as professional skiers, the incidence of knee injury is twice as high for women, and their risk of ACL injury is 3 times as high. ${ }^{6,16,23}$ Reported possible reasons for the difference between men and women are related to extrinsic factors on one hand, such as level of conditioning, neuromuscular factors, and muscle strength, ${ }^{13,25}$ and intrinsic factors on the other, such as pelvis width, tibial rotation, physiologic laxity, and the effects of hormones, especially estrogen. ${ }^{14,18,25}$ Although Flørenes et $\mathrm{al}^{8}$ reported that the incidence of injuries in alpine skiing is higher with increased speed ( $50 \%$ of knee injuries in downhill vs $6 \%$ in slalom), there is no difference in the occurrence rate of ACL tears between technical and speed disciplines in the alpine skiers of the French national team. In men, incidences between the number of ACL injuries and the number of skier-years in technical and speed disciplines are the same $\left(i_{\text {speed }}=i_{\text {technical }}=3 \%\right)$. In women, there is a slightly higher incidence in speed disciplines $\left(i_{\text {speed }}=5 \%\right)$ as compared with technical disciplines $\left(i_{\text {technical }}=4 \%\right)$. This result shows that there is a maximum speed intrinsic to the discipline (whether technical or speed) that leads skiers to regularly reach the limit if they want to be at the top world level. Note that the incidences of knee injuries reported by Flørenes and collaborators ${ }^{8}$ include all types of injuries and not only ACL tears.

\section{Career Length}

From 1980 to 2013, the career length of French alpine skiers is different between G1 and G2. In fact, the mean 
career length of G1 skiers is longer than that of G2 skiers. The same trend is observed for women, with a longer career length for G1 skiers compared with G2 skiers. These results confirm those reported by Pujol et al, ${ }^{23}$ which show that career length for skiers who suffered an ACL tear is significantly longer than for those who did not. This could be explained in part by the time required for the recovery and reconstruction of the ACL of injured skiers, which extends their career length in the national team. Furthermore, after the time of recovery, trainers establish a necessary regulation of the volume and load training for skiers in return after injury. In our cohort, a longer career $(9.1 \pm 4.6$ years $)$ is noted among skiers who had multiple ACL tears compared with those who had only 1 (7.2 \pm 4.5 years). The majority of skiers with better performances (69.4\%) after the injury had 1 rupture; only $22.2 \%$ had a new rupture in the same knee; and $16.7 \%$ had bilateral rupture. Another hypothesis justifying that G1 skiers have longer careers is the talent. G1 athletes could be more skilled than their counterparts without injury and thus lengthen their sporting careers. Today, career management and, therefore, career duration require considering these recurrences in particular because of the association of age with the recurrence. ${ }^{26}$

\section{ACL Rupture and Return to Sport}

Other parameters were evaluated after ACL reconstruction, such as intending to return to the same sport/level, playing a different sport (from that of preinjury), or otherwise stopping any sport participation. ${ }^{1,10}$ In addition, factors influencing postoperative return to sport after an ACL rupture have been studied.,24 The functional measurement of the knee was also taken into account. Ardern et $\mathrm{al}^{1}$ measured these parameters in several sports: soccer, Australian football, netball, and basketball. Forty-five percent returned to sport at the same level of participation, and $29 \%$ returned to competition. In another study, Ardern et $\mathrm{al}^{2}$ showed that at 12 months after ACL surgery, 67\% did not return to competitive sport, and only $33 \%$ tried to return to competition. Our results show that the time necessary to achieve better performance after ACL rupture is on average 3.8 years for men and 3.1 years for women. Skiers in speed disciplines come back faster than skiers in technical disciplines (men, 3.6 vs 4.1 years; women, 2.9 vs 3.3 years).

In a qualitative study, Tjong et $\mathrm{al}^{26}$ analyzed the rate of the return to sport and the factors affecting this return after an ACL reconstruction. They showed that $64 \%$ of patients had not returned to their preinjury levels and only $36 \%$ had. Moreover, there is no link between the functional recovery of the knee after ACL rupture and participation level or competition level before ACL rupture. ${ }^{1,2}$ Finally, in all sports, men are not more likely than women to return to sport after an ACL tear, and the rate of return to sport after an ACL tear is not different ${ }^{1}$ between men and women, as in our population. However, women return to a better level more so than the men $(75.7 \%$ vs $65.7 \%$, respectively).

\section{Methodological Considerations}

This is an exhaustive study because it takes into account all French skiers since 1980. It represents the first epidemiologic study based on FIS points, the world FIS ranking, and podium finishes to analyze the influence of ACL injury in competitive alpine skiing. The FIS points system, representing the main performance indicator of the study, has been regular and consistent since 1995. However, skiers may have suffered injuries other than ACL rupture during their careers. The 4 specialties were categorized by speed disciplines (downhill and super-G) and technical disciplines (giant slalom and slalom) to have a more rigorous number of subjects by sample. Finally, we do not have FIS points and world FIS rankings before 1995.

\section{CONCLUSION}

Skiers are able to achieve better FIS points, better world rankings, and more podium finishes after an ACL tear. All skiers who had ACL tears continued their competitive careers after the injury. The moment when the ACL rupture occurs during the career influences the postinjury performance. The probability of obtaining better performance after this injury is higher if the rupture and subsequent recovery occur before the peak-performance age of 25 years.

\section{ACKNOWLEDGMENT}

The authors thank the National Institute of Sports Expertise and Performance teams for their full support and the Fédération Franæaise de Ski and ED 556 HSRT for their great interest in this work. The authors also thank Ms Emilie Janton for her helpful comments and critical reading of the article.

\section{REFERENCES}

1. Ardern CL, Taylor NF, Feller JA, Webster KE. Return-to-sport outcomes at 2 to 7 years after anterior cruciate ligament reconstruction surgery. Am J Sports Med. 2012;40:41-48.

2. Ardern CL, Webster KE, Taylor NF, Feller JA. Return to the preinjury level of competitive sport after anterior cruciate ligament reconstruction surgery: two-thirds of patients have not returned by 12 months after surgery. Am J Sports Med. 2011;39:538-543.

3. Baker AB, Tang YQ. Aging performance for masters records in athletics, swimming, rowing, cycling, triathlon, and weightlifting. Exp Aging Res. 2010;36:453-477.

4. Berthelot $G$, Len $S$, Hellard $P$, et al. Exponential growth combined with exponential decline explains lifetime performance evolution in individual and human species. Age. 2012;34:1001-1009.

5. Bouter LM, Knipschild PG, Feij JA, Volovics A. Sensation seeking and injury risk in downhill skiing. Pers Individ Dif. 1988;9:667-673.

6. Burtscher M, Gatterer H, Flatz M, et al. Effects of modern ski equipment on the overall injury rate and the pattern of injury location in Alpine skiing. Clin J Sport Med. 2008;18:355-357.

7. Eastlack ME, Axe MJ, Snyder-Mackler L. Laxity, instability, and functional outcome after ACL injury: copers versus noncopers. Med Sci Sports Exerc. 1999;31:210-215. 
8. Flørenes TW, Bere T, Nordsletten L, Heir S, Bahr R. Injuries among male and female World Cup alpine skiers. $\mathrm{Br} J$ Sports Med. 2009;43:973-978.

9. Flørenes TW, Nordsletten L, Heir S, Bahr R. Recording injuries among World Cup skiers and snowboarders: a methodological study. Scand J Med Sci Sports. 2011;21:196-205.

10. Greenwood JD, Moses GE, Bernardino FM, Gaesser GA, Weltman A. Intensity of exercise recovery, blood lactate disappearance, and subsequent swimming performance. J Sports Sci. 2008;26:29-34

11. Guillaume M, Len S, Tafflet M, et al. Success and decline: top 10 tennis players follow a biphasic course. Med Sci Sports Exerc. 2011;43:2148-2154.

12. Heijne A, Axelsson K, Werner S, Biguet G. Rehabilitation and recovery after anterior cruciate ligament reconstruction: patients' experiences. Scand J Med Sci Sports. 2008;18:325-335

13. Heyman E, DE Geus B, Mertens I, Meeusen R. Effects of four recovery methods on repeated maximal rock climbing performance. Med Sci Sports Exerc. 2009;41:1303-1310.

14. Hunter RE. Skiing injuries. Am J Sports Med. 1999;27:381-389.

15. Huston LJ, Wojtys EM. Neuromuscular performance characteristics in elite female athletes. Am J Sports Med. 1996;24:427-436.

16. Hutchinson MR, Ireland ML. Knee injuries in female athletes. Sports Med. 1995;19:288-302.

17. International Ski Federation. http://data.fis-ski.com/alpine-skiing/ biographies.html. Accessed March 1, 2014.

18. Johnson RJ, Zucco P, Shealy JE. Skiing Trauma and Safety. Vol 13. West Conshohocken, PA: ASTM International; 2000.

19. Lafollie D. [Detection of high-risk personalities in risky sports]. Encephale. 2007;33:135-141.

20. Lund-Hanssen H, Gannon J, Engebretsen L, Holen KJ, Anda S, Vatten L. Intercondylar notch width and the risk for anterior cruciate ligament rupture: a case-control study in 46 female handball players. Acta Orthop Scand. 1994;65:529-532.

21. Moore $\mathrm{DH} 2$ nd. A study of age group track and field records to relate age and running speed. Nature. 1975;253:264-265.

22. Osborn ZH, Blanton PD, Schwebel DC. Personality and injury risk among professional hockey players. J Inj Violence Res. 2009;1:1519.

23. Pujol N, Rousseaux-Blanchi MP, Chambat P. The incidence of anterior cruciate ligament injuries among competitive Alpine skiers: a 25-year investigation. Am J Sports Med. 2007;35:10701074.

24. Schaal K, Tafflet $\mathrm{M}$, Nassif $\mathrm{H}$, et al. Psychological balance in high level athletes: gender-based differences and sport-specific patterns. PLoS One. 2011;6:e19007.

25. Stevenson H, Webster J, Johnson R, Beynnon B. Gender differences in knee injury epidemiology among competitive alpine ski racers. lowa Orthop J. 1998;18:64-66.

26. Tjong VK, Murnaghan ML, Nyhof-Young JM, Ogilvie-Harris DJ. A qualitative investigation of the decision to return to sport after anterior cruciate ligament reconstruction to play or not to play. $A m J$ Sports Med. 2014;42:336-342.

27. Viola RW, Steadman JR, Mair SD, Briggs KK, Sterett WI. Anterior cruciate ligament injury incidence among male and female professional alpine skiers. Am J Sports Med. 1999;27:792-795.

28. Webster KE, Feller JA, Leigh WB, Richmond AK. Younger patients are at increased risk for graft rupture and contralateral injury after anterior cruciate ligament reconstruction. Am J Sports Med. 2014;42:641-647.

29. Zuckerman M, Eysenck SBJ, Eysenck HJ. Sensation seeking in England and America: cross-cultural, age, and sex comparisons. J Consult Clin Psychol. 1978;46:139-149. 